\title{
Water soluble nano-scale transient material germanium oxide for zero toxic waste based environmentally benign nano-manufacturing
}

A. S. Almuslem, A. N. Hanna, T. Yapici, N. Wehbe, E. M. Diallo, A. T. Kutbee, R. R. Bahabry, and M. M. Hussain

Citation: Appl. Phys. Lett. 110, 074103 (2017); doi: 10.1063/1.4976311

View online: http://dx.doi.org/10.1063/1.4976311

View Table of Contents: http://aip.scitation.org/toc/apl/110/7

Published by the American Institute of Physics

\section{Articles you may be interested in}

Zinc tin oxide metal semiconductor field effect transistors and their improvement under negative bias (illumination) temperature stress

Appl. Phys. Lett. 110, 073502073502 (2017); 10.1063/1.4976196

Room-temperature vertical-cavity surface-emitting lasers at $4 \mu \mathrm{m}$ with GaSb-based type-Il quantum wells Appl. Phys. Lett. 110, 071104071104 (2017); 10.1063/1.4975813

Electrically driven and electrically tunable quantum light sources

Appl. Phys. Lett. 110, 071102071102 (2017); 10.1063/1.4976197

Tamper indicating gold nanocup plasmonic films

Appl. Phys. Lett. 110, 071101071101 (2017); 10.1063/1.4975936 \\ Applied Physics Reviews}

SAVE THE DATE!

3D Bioprinting: Physical and Chemical Processes May 2-3, 2017 Winston Salem, NC, USA 


\title{
Water soluble nano-scale transient material germanium oxide for zero toxic waste based environmentally benign nano-manufacturing
}

\author{
A. S. Almuslem, ${ }^{1}$ A. N. Hanna, ${ }^{1}$ T. Yapici, ${ }^{2}$ N. Wehbe,${ }^{2}$ E. M. Diallo, ${ }^{2}$ A. T. Kutbee,${ }^{3}$ \\ R. R. Bahabry, ${ }^{3}$ and M. M. Hussain ${ }^{1, a)}$ \\ ${ }^{1}$ Integrated Nanotechnology Lab and Integrated Disruptive Electronic Applications (IDEA) Lab, \\ Electrical Engineering, Computer Electrical Mathematical Science and Engineering Division, \\ King Abdullah University of Science and Technology (KAUST), Thuwal 23955-6900, Saudi Arabia \\ ${ }^{2}$ Analytical Chemistry Lab and Imaging and Characterization Lab, KAUST Core Facilities, KAUST, Thuwal, \\ Saudi Arabia \\ ${ }^{3}$ Integrated Nanotechnology Lab and Integrated Disruptive Electronic Applications (IDEA) Lab, \\ Material Science and Engineering, Physical Science and Engineering Division, King Abdullah University of \\ Science and Technology (KAUST), Thuwal 23955-6900, Saudi Arabia
}

(Received 4 December 2016; accepted 25 January 2017; published online 14 February 2017)

\begin{abstract}
In the recent past, with the advent of transient electronics for mostly implantable and secured electronic applications, the whole field effect transistor structure has been dissolved in a variety of chemicals. Here, we show simple water soluble nano-scale (sub-10 nm) germanium oxide $\left(\mathrm{GeO}_{2}\right)$ as the dissolvable component to remove the functional structures of metal oxide semiconductor devices and then reuse the expensive germanium substrate again for functional device fabrication. This way, in addition to transiency, we also show an environmentally friendly manufacturing process for a complementary metal oxide semiconductor (CMOS) technology. Every year, trillions of complementary metal oxide semiconductor (CMOS) electronics are manufactured and billions are disposed, which extend the harmful impact to our environment. Therefore, this is a key study to show a pragmatic approach for water soluble high performance electronics for environmentally friendly manufacturing and bioresorbable electronic applications. Published by AIP Publishing.

[http://dx.doi.org/10.1063/1.4976311]
\end{abstract}

Transient electronics have received growing attention recently owing to its dissolvability for implantable and secured electronic applications. ${ }^{1,2}$ In these examples, the whole structure is dissolved over the time in a variety of chemicals. Here, we show that water soluble germanium dioxide $\left(\mathrm{GeO}_{2}\right)$ can be employed as a transient material besides its function as a dielectric layer. The usage of $\mathrm{GeO}_{2}$ as the dissolvable material will still remove the key structure to serve the purpose of dissolution. At the same time, since it is simply water soluble, we can reuse the expensive germanium $(\mathrm{Ge})$ substrate for further device fabrication.

$\mathrm{GeO}_{2}$ can have three forms, two of them are crystalline and the third one is vitreous. Crystalline forms are represented by hexagonal and tetragonal crystalline structures. ${ }^{3}$ The growth conditions determine the resultant form of $\mathrm{GeO}_{2}$, and the difference between them was reported by Johnson. ${ }^{4}$ Only hexagonal and vitreous form is water soluble. The hydrolysis mechanism of $\mathrm{GeO}_{2}$ undergoes the following chemical reaction: ${ }^{5}$

$$
\mathrm{GeO}_{2(s)}+\mathrm{H}_{2} \mathrm{O}_{(l)} \leftrightarrow \mathrm{H}_{2} \mathrm{GeO}_{3(a q .)}
$$

Surface oxidation of Ge has been considered as an undesirable feature, which prevents Ge to be incorporated in the Complementary Metal Oxide Semiconductor (CMOS) industry for a long time. However, many studies have addressed a surface passivation challenge for the purpose of making use of superior material properties of Ge. Ge possesses favorable

\footnotetext{
${ }^{\text {a) }}$ Author to whom correspondence should be addressed. Electronic mail: muhammadmustafa.hussain@kaust.edu.sa
}

properties such as high carrier mobility (up to $3900 \mathrm{~cm}^{2} \mathrm{~V}^{-1}$ $\mathrm{s}^{-1}$ for electrons and $1900 \mathrm{~cm}^{2} \mathrm{~V}^{-1} \mathrm{~s}^{-1}$ for holes), ${ }^{6}$ direct and small energy band gap $(0.66 \mathrm{eV})$, small optical band gap (wide absorption wavelength spectrum), and low dopant thermal activation energies in comparison with the universal CMOS material Silicon $(\mathrm{Si}){ }^{7}$ As a result of unique properties, Ge becomes the material of choice for manufacturing high speed, low power devices, ${ }^{8}$ as well as optoelectronic devices. ${ }^{9}$

In this work, water soluble $\mathrm{GeO}_{2}$ is a hallmark since it serves two different purposes as it allows for both recycling the substrate and reducing the pollution originated from discarded consumer electronics. We show that it would be of great benefit to meet the rapid growth demands for consumer electronics and keeping the electronic waste at bay simultaneously. Electronic waste is reported to be up to $42 \times 10^{6}$ tons yearly. ${ }^{10}$ Moreover, water as an etchant of $\mathrm{GeO}_{2}$ is highly preferable to other wet reactive chemicals as water is used frequently in the IC fabrication process for cleaning and etching purposes because: (i) it does not have an environmental impact, (ii) it is safe to handle easily, and (iii) it is relatively of low-cost. ${ }^{11}$ On the other hand, the $\mathrm{Ge} / \mathrm{GeO}_{2}$ interface has a variety of satisfactory properties such as acceptable dielectric constant $(\kappa=2.8),{ }^{12}$ moderate refractive index, and adequate thermal stability. ${ }^{13}$ Besides that, $\mathrm{GeO}_{2}$ has the advantage of suppressing the $\mathrm{Ge}$ dangling bond at the surface, which in turn minimizes the interface trap density. ${ }^{14}$

In this study, Metal Oxide Semiconductor Capacitors (MOSCAPs) are built on p-type Ge substrates using $\mathrm{GeO}_{2}$ as 
a dielectric layer. After characterizing the capacitors, the substrate is rinsed with tap water in order to dissolve $\mathrm{GeO}_{2}$, which in turn takes away all the top layers. The substrate is then effectively reused to build the similar MOSCAPs again. $\mathrm{GeO}_{2}$ is thermally grown on a p-type Ge (Ga-doped) $175 \mu \mathrm{m}$ thick substrate with resistivity ranging from 0.01 to $0.05 \Omega \mathrm{cm}$.

We start with 4-in. Ge wafer, which is then diced up to $2 \times 2 \mathrm{~cm}^{2}$ experimental samples. Then, the pieces are cleaned with HF (49\%), rinsed with Deionized (DI) water, blown dried in Nitrogen $\left(\mathrm{N}_{2}\right)$, followed by acetone and isopropanol based cleaning, and blown dried in $\mathrm{N}_{2}$. After that, the processed experimental samples are transferred into an Ultra High Vacuum Chemical Vapor Deposition (UHVCVD) chamber in order to grow $\mathrm{GeO}_{2}$. The chamber's temperature is stabilized at $400{ }^{\circ} \mathrm{C}$ for $4 \mathrm{~h}$ in Oxygen $\left(\mathrm{O}_{2}\right)$ ambient with a flow rate of $100 \mathrm{sccm}$.

X-ray Photoemission Spectroscopy (XPS) was used to verify the substrate surface properties for a clean Ge surface, grown $\mathrm{GeO}_{2}$ layer, $\mathrm{GeO}_{2}$ removal, and regrown $\mathrm{GeO}_{2}$ layer as it is capable to provide the chemical composition. ${ }^{15}$ XPS experiments were performed on a KRATOS Analytical AMICUS instrument equipped with an achromatic $\mathrm{Al} \mathrm{K} \alpha$ $\mathrm{X}$-ray source $(1468.6 \mathrm{eV})$. Typically, the source was operated at a voltage of $10 \mathrm{kV}$ and a current of $10 \mathrm{~mA}$. The pressure in the analysis chamber was below $4 \times 10^{-6} \mathrm{~Pa}$. In XPS, it is well known that $2 p_{3 / 2}$ and $3 d_{5 / 2}$ photoemission lines of the elemental $\mathrm{Ge}$ are detected at $1217.3 \mathrm{eV}$ and $29.3 \mathrm{eV}$, respectively, and any peak shift in the binding energy is related to altering the oxidation state of Ge. XPS data recorded for a clean germanium sample and for the processed samples are compared in Fig. 1(a). The three processed samples refer to post $\mathrm{GeO}_{2}$ growth $\left(\mathrm{GeO}_{2}\right.$ grown on pristine $\mathrm{Ge}$ after cleaning), post $\mathrm{GeO}_{2}$ removal, and post $\mathrm{GeO}_{2}$ re-growth
( $\mathrm{GeO}_{2}$ grown after the first $\mathrm{GeO}_{2}$ has been removed). XPS peaks of $\mathrm{GeO}_{2}$ grown and $\mathrm{GeO}_{2}$ regrown samples are identical and reveal a clear shift with respect to the reference sample. Indeed, the $2 \mathrm{p}_{3 / 2}$ and $3 \mathrm{~d}_{5 / 2}$ photoemission lines are shifted by $2.8 \mathrm{eV}$ and $3.5 \mathrm{eV}$, respectively, toward higher binding energy, which is specified to the fourth oxidation state $\left(\mathrm{Ge}^{+4}\right)$ of $\mathrm{Ge}$ and confirms the existence of the $\mathrm{GeO}_{2}$ layer. ${ }^{7,13,16,17}$ However, the spectrum acquired for the reference germanium substrate is very similar to the one belonging to the rinsed sample, suggesting that both layers have the same composition. The quantitative data indicate that the reference and rinsed samples are composed of almost $50 \%$ of germanium and $50 \%$ of oxygen, whereas the grown and regrown layers contain $67 \%$ of oxygen and $33 \%$ of germanium. Precisely speaking, the major components of Ge $2 p_{3 / 2}$ and $\mathrm{Ge} 3 \mathrm{~d}_{5 / 2}$ of the reference and rinsed samples are detected, respectively, at $1218 \mathrm{eV}$ and $29.6 \mathrm{eV}$. These values can be assigned to metallic germanium Ge., ${ }^{7,13,16}$ The smaller component detected mainly for $\mathrm{Ge} 2 \mathrm{p}_{3 / 2}$ at 1219.8 can be assigned to germanium monoxide $(\mathrm{GeO})$. Hence, the most probable chemical composition of both reference and rinsed layers can be described by a thin over layer of native germanium monoxide $(\mathrm{GeO})$ covering the metallic germanium. In contrast, the major components of $\mathrm{Ge} 2 \mathrm{p}_{3 / 2}$ and $\mathrm{Ge}$ $3 \mathrm{~d}_{5 / 2}$ of the grown and regrown samples are detected, respectively, at $1221.2 \mathrm{eV}$ and $32.8 \mathrm{eV}$. These values can be clearly assigned to germanium dioxide $\mathrm{GeO}_{2}{ }^{7,13,16,17}$ The intensity of the $\mathrm{Ge} 3 \mathrm{~d}$ component measured at $29.3 \mathrm{eV}$ for the regrown layer is slightly higher than that measured for the grown one, suggesting that the regrown $\mathrm{GeO}_{2}$ layer is thinner.

Knowledge of the $\mathrm{Ge} / \mathrm{GeO}_{2}$ interface is essential for evaluating the quality of the growth method. A valuable insight into the $\mathrm{Ge} / \mathrm{GeO}_{2}$ interface is obtained from TEM
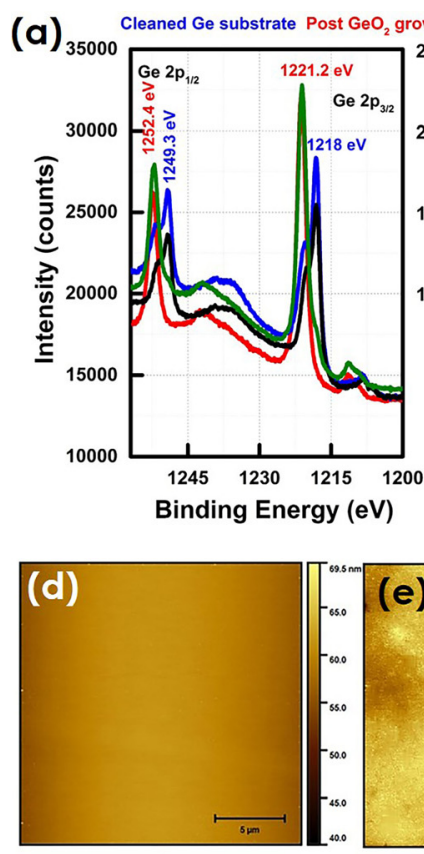

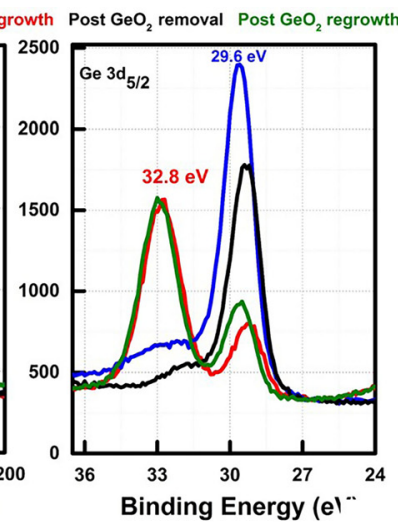

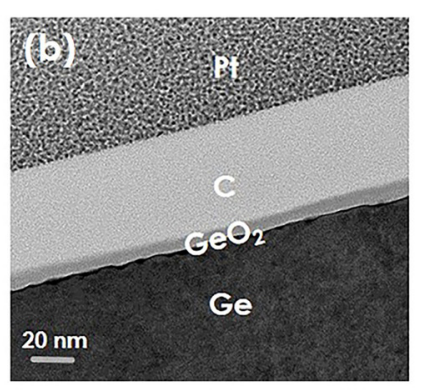
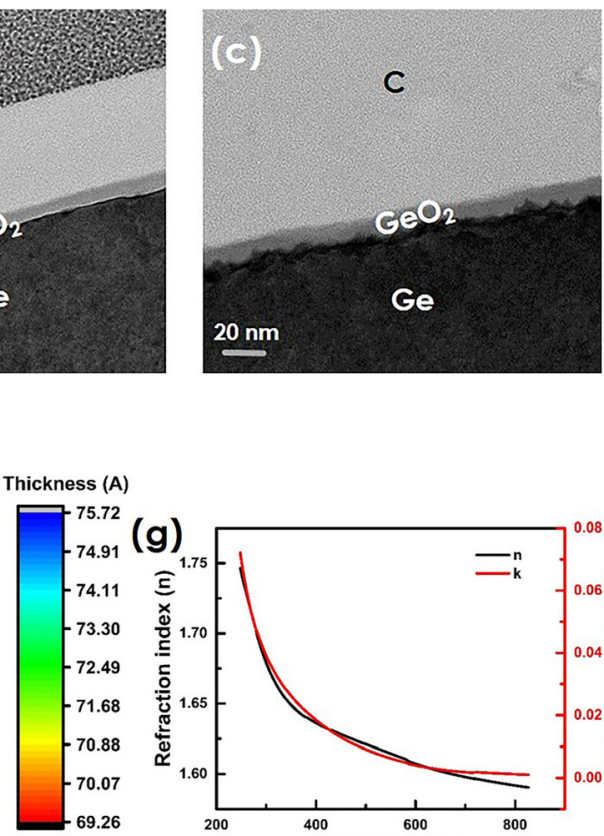

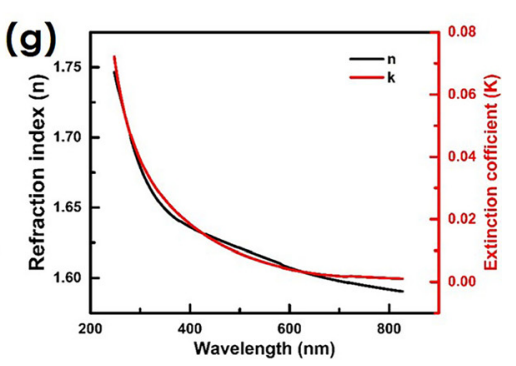

FIG. 1. (a) High resolution XPS spectra of Ge 2p and Ge $3 \mathrm{~d}$ peaks acquired for the reference Ge substrate, for the grown GeO ${ }_{2}$ layer, for the same layer after submerging into tap water for 3 days, and for the re-grown $\mathrm{GeO}_{2}$ layer after water based removal. (b) and (c) TEM images of GeO $\mathrm{O}_{2}$ for post-growth and postre-growth samples, respectively. (d) and (e) AFM images of grown and regrown $\mathrm{GeO}_{2}$ layers, respectively. (f) Thickness variation of $\mathrm{GeO}_{2}$ across $10.76 \mathrm{~mm}{ }^{2}$ by spectroscopic ellipsometry. (g) Refraction index and extinction coefficient of $\mathrm{GeO}_{2}$. 
images (Figs. 1(b) and 1(c)), which show a discontinuity free $\mathrm{GeO}_{2}$ layer with a clear and slightly zig zag $\mathrm{Ge} / \mathrm{GeO}_{2}$ interface in both cases of post $\mathrm{GeO}_{2}$ growth and post-regrowth $\mathrm{GeO}_{2}$ samples. However, the surface of the $\mathrm{Ge}$ substrate becomes rougher after regrown $\mathrm{GeO}_{2}$ and that introduces pronounced variation in the $\mathrm{GeO}_{2}$ thickness. Atomic force microscopy (AFM) is employed to obtain the topographic imaging of $400 \mu \mathrm{m}^{2}$ surface area of $\mathrm{GeO}_{2}$ (Figs. 1(d) and 1(e)) and the RMS roughness found to be $1.89 \mathrm{~nm}$ and $5 \mathrm{~nm}$ for post $\mathrm{GeO}_{2}$ growth and post-regrowth $\mathrm{GeO}_{2}$, respectively. The thickness uniformity of the thermally grown $\mathrm{GeO}_{2}$ layer is examined using spectroscopic ellipsometry. The map of the scanned area of $10.76 \mathrm{~mm}^{2}$ reveals uniform growth of germanium dioxide with an average thickness of $7.2 \pm 0.3 \mathrm{~nm}$ variation across the scanned area (Fig. 1(f)). The optical constants representing the refraction index (n) and extinction coefficient (K) of the $\mathrm{GeO}_{2}$ layer have been measured and depicted in Fig. 1(g). A couple of features of this plot are worth pointing out. First, the measured refractive index at $550 \mathrm{~nm}$ is equal to 1.6 , which is in total agreement with the reported value in previous studies. ${ }^{13,18}$ Furthermore, the maximum value of the extinction coefficient $(\mathrm{K})$ of $\mathrm{GeO}_{2}$ is observed at $246 \mathrm{~nm}$, which means that $\mathrm{GeO}_{2}$ has a tendency to be highly absorbing at $246 \mathrm{~nm}$.

In order to get accurate information about the dissolution rate of $\mathrm{GeO}_{2}$, Emission-spectrometric detection of the elements at the ultra-trace level using inductively coupled plasma optical emission spectrometry (ICP-OES) is hired. The dissolution rate is systematically studied at different temperatures within the range of $\mathrm{T}=23^{\circ} \mathrm{C}$ and $\mathrm{T}=70^{\circ} \mathrm{C}$ for tap water, DI water, and Phosphate Buffered Solutions (PBS). The $\mathrm{GeO}_{2}$ is thermally grown on p-type Ge pieces that have the same size $\left(1 \times 1 \mathrm{~cm}^{2}\right)$. Then, every piece is submerged into $100 \mathrm{ml}$ of a solution in a sealed Teflon bottle, which is placed in a thermal water bath at steady temperature. Later, $5 \mathrm{ml}$ of the solution is drawn every couple of hours and used to measure the concentration of Ge ions. In more detail, the solution is fed into a $50-\mathrm{MHz}$ radio frequency (RF) induced argon plasma chamber from sample introduction nebulization systems, which is exposed to an elevated temperature up to approximately $7000-8000 \mathrm{~K}$. At such atmosphere, all the analyte species are thermally excited through collisional excitation within the plasma. A photon at quantized energy is released when the atomic and ionic excited state species relax to the ground state, which in turn is used to identify the analyte species from which they originated. The concentration of the analyte species is directly proportional to the total number of photons. ${ }^{19}$ The detected wavelengths are equal to $219.871 \mathrm{~nm}, 204.377 \mathrm{~nm}$, $259.253 \mathrm{~nm}, 209.426 \mathrm{~nm}, 265.117 \mathrm{~nm}$, and $206.866 \mathrm{~nm}$, which is certainly a fingerprint of Ge ions. ${ }^{20}$ This demonstrates the removal of $\mathrm{GeO}_{2}$ by dissolution with well-defined kinetics. The concentration of Ge ions is measured for all stipulated wavelengths. Then, the average of the concentration is plotted as a function of time (Figs. 2(a)-2(c)). The slope of solubility curves in linear regimes represents the dissolution rate of $\mathrm{GeO}_{2}$. The dissolution rate of $\mathrm{GeO}_{2}$ is plotted at different temperatures for tap water, DI water, and PBS solution as depicted in Fig. 2(d). Fig. 2(d) sheds some light on the dissolution rate of $\mathrm{GeO}_{2}$ from different aspects. First of all, there is a highly significant distinction between the dissolution rate of $\mathrm{GeO}_{2}$ in tap water on one side and DI water and PBS solutions on the other side. Further, the dissolution rate of $\mathrm{GeO}_{2}$ increases remarkably with temperature in tap water, whereas it increases slightly in DI water and PBS solutions, as well. As a result, the dissolution rate of $\mathrm{GeO}_{2}$ could be controlled based on the temperature and $\mathrm{pH}$ values of the solution. From the chemistry point of view, the three solutions used in this study differ from each other in the $\mathrm{pH}$ value. The tap water has the highest $\mathrm{pH}$ value (8.9) among (a)
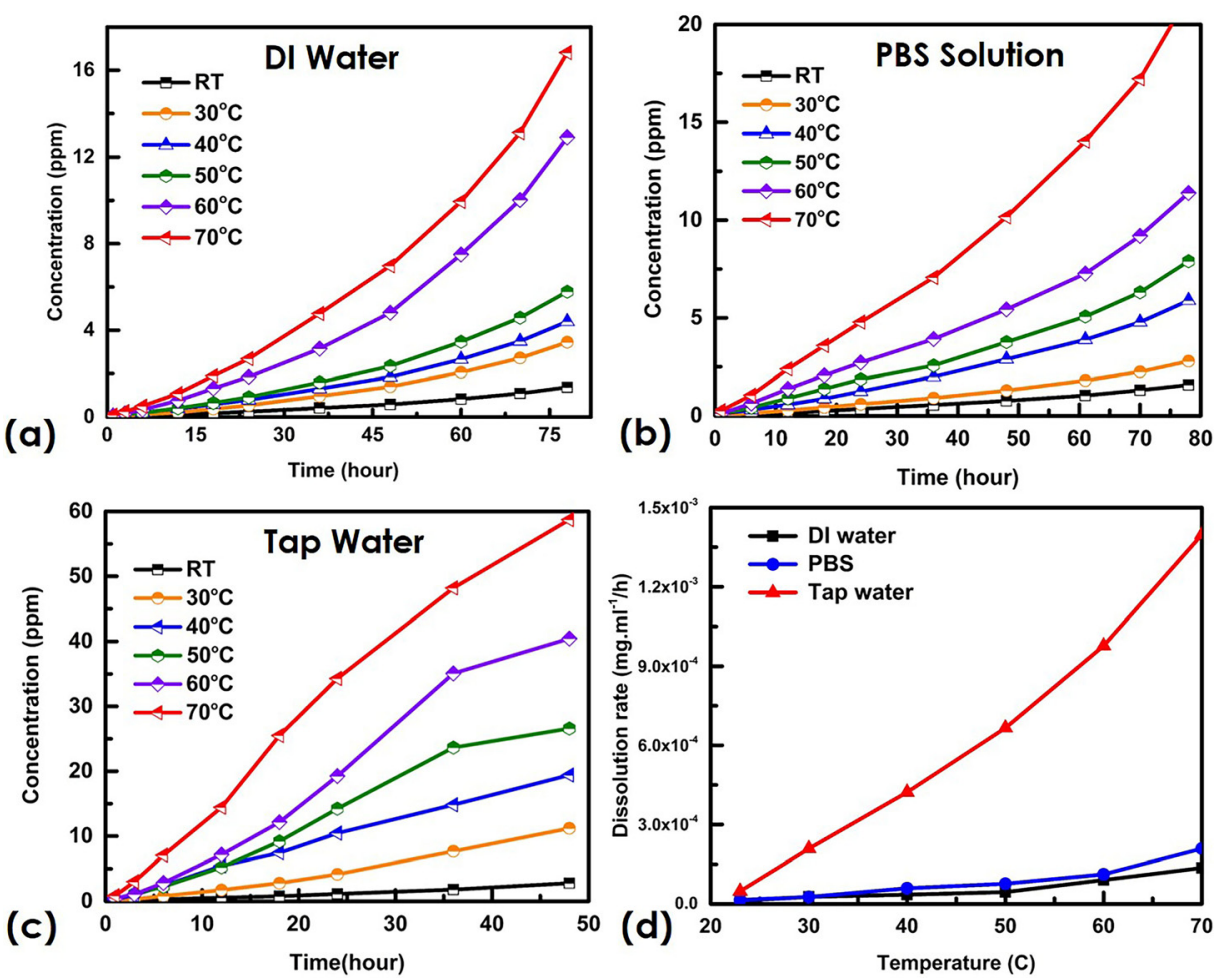

FIG. 2. (a)-(c) Concentration of Ge ions measured by (ICP-OES). (b) Dissolution rate of $\mathrm{GeO}_{2}$. 
other employed solutions and has a clear impact on speeding up the dissolution rate of $\mathrm{GeO}_{2}$ (Fig. 2(d)). The $\mathrm{pH}$ value indicates that tap water has a higher relative number of hydroxyl ions $\left(\mathrm{OH}^{-}\right)$in comparison to DI water $(\mathrm{pH}=6.6)$ and $\mathrm{PBS}(\mathrm{pH}=7.4) . \mathrm{OH}^{-}$ions are of great importance to initiate the hydrolysis reaction of $\mathrm{GeO}_{2}$ with water. Strictly speaking, the physical properties, in particular, the ionic charge $\mathrm{z}$ and the ionic radius of the material, will determine under which $\mathrm{pH}$ value will the material hydrolyze. ${ }^{21}$ Additionally, the presence of $\mathrm{OH}^{-}$ion in the solution will speed up the hydrolysis reaction because the reactivity of $\mathrm{OH}^{-}$ions is four orders of magnitude greater than $\mathrm{H}_{2} \mathrm{O}{ }^{22} \mathrm{In}$ future, the scope of the influence of $\mathrm{pH}$ needs to be studied in more detail. On the other hand, the solution's temperature can accelerate the dissolution rate, which can be explained based on the kinetic molecular theory and the temperature dependence of reaction rate constant, which in turn quantifies the rate of a chemical reaction. ${ }^{23}$

MOSCAPs (with area $2.19 \times 10^{-4} \mathrm{~mm}^{2}$ ) are fabricated in order to study the utility of $\mathrm{GeO}_{2}$ as a dielectric layer in the case of post $\mathrm{GeO}_{2}$ growth and post-regrowth samples. The process flow starts with the Ge substrate that is first diced to $2 \times 2 \mathrm{~cm}^{2}$ pieces and cleaned with acetone and isopropanol. Then, Ti $(40 \mathrm{~nm}) / \mathrm{Pt}(60 \mathrm{~nm})$ is sputtered in the backside to serve as a back electrode and to prevent $\mathrm{GeO}_{2}$ from growing on the backside of the pieces. Then, $\mathrm{GeO}_{2}$ is grown. Later on, sputtered $\mathrm{Al}(250 \mathrm{~nm})$ is patterned through a shadow mask to serve as a gate electrode Fig. 3(a). The data of CV measurement were collected by an LCR meter at $1 \mathrm{MHz}$. After characterizing the MOS capacitors, the piece is immersed into a tap water at RT and sonicated for $60 \mathrm{~min}$ every $24 \mathrm{~h}$ for three days with replacing the water daily. The dissolution of the $\mathrm{GeO}_{2}$ layer starts at the exposed area and at the edge of the Al patterned layer, which in turn facilitates removing the Al layer (Fig. 3(b)). Then, the pieces were examined by XPS to verify the absence of $\mathrm{GeO}_{2}$. Later, the piece is treated exactly as the first time in order to clean it and rebuild the MOSCAPs. The $\mathrm{C}-\mathrm{V}$ characteristics of capacitors in both cases (post $\mathrm{GeO}_{2}$ growth and post-regrowth samples) are shown in Fig. 3(c). For the first-time growth sample, we notice a capacitance value of $495 \mathrm{pF}$ for devices. For the purpose of extracting the value of dielectric constant of the $\mathrm{GeO}_{2}$ layer, the universal equation is employed

$$
C=\frac{\kappa \varepsilon_{0} A}{\mathrm{~d}},
$$

where $\kappa$ is the dielectric constant, $\varepsilon_{0}$ is the vacuum permittivity, $\mathrm{A}$ is the device area, and $\mathrm{d}$ is the dielectric thickness. According to the thickness scan map shown in Fig. 1(f), the $\mathrm{d}$ value of $7.2 \mathrm{~nm}$ has been chosen for the calculation of $\kappa$. The calculated value came to be $\sim 1.84$, which is consistent with the previous literature, ${ }^{18}$ showing similar dielectric properties as shown from ellipsometry data, Figs. 1(g) and 3(d), where the increase in the dielectric constant for photon energies larger than $3 \mathrm{eV}$ is attributed to sub-bandgap photoabsorption due to significant density of gap states. The existence of mid-gap states could also explain the bump shown in the CV curve in Fig. 3(c). ${ }^{24}$ After the regrowth of the $\mathrm{GeO}_{2}$ layer, the oxide capacitance becomes $43 \%$ higher than the original value. Spectroscopic ellipsometry data (Fig. 3(d)) have shown the dielectric constant of the regrown sample to be identical to that of the first-time growth. Therefore, using the extracted dielectric constant from the first growth capacitance measurement, 1.84, we extracted a dielectric thickness of $\sim 5 \mathrm{~nm}$ and this was confirmed by the spectroscopic ellipsometry measurement. This proves that the thickness reduction of $\mathrm{GeO}_{2}$ is behind the $43 \%$ higher capacitance after regrowth. We have independently calculated the dielectric constant using the $\mathrm{C}-\mathrm{V}$ measurements and measured film thicknesses for post-growth and post-regrowth samples, which yielded a similar dielectric constant (Figure S1 in the supplementary material).

We have shown how water soluble sub- $10 \mathrm{~nm} \mathrm{GeO}$ can be effectively used for environmentally benign zero toxic waste CMOS manufacturing for scaled high performance CMOS electronics, transient electronics for water solvable low-cost transient sensory systems.



(c)

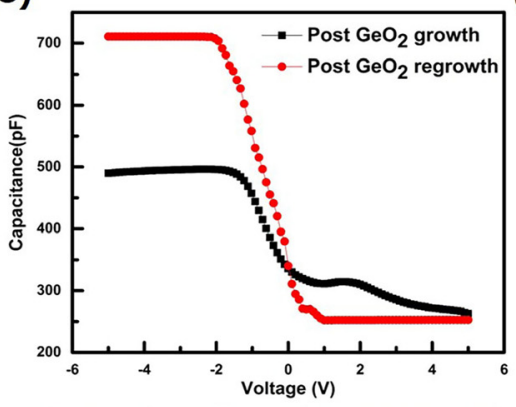

(b)
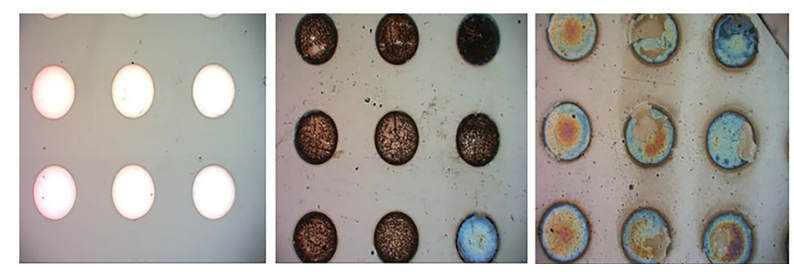

(d)
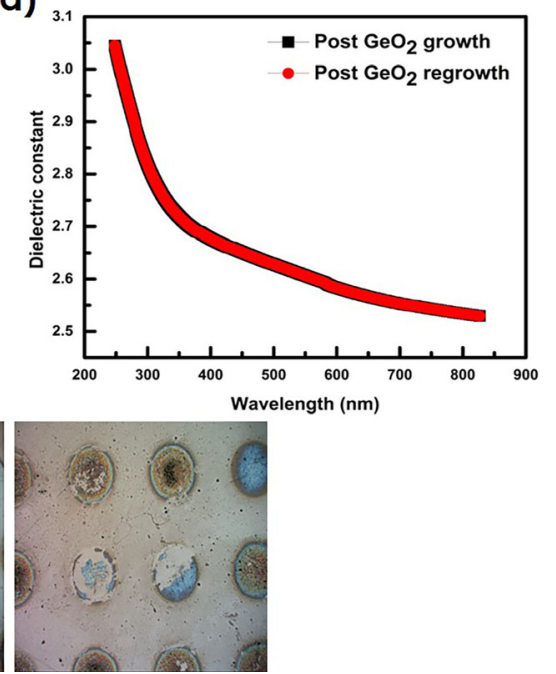

FIG. 3. (a) Fabrication flow of MOS capacitors. (b) Chronological optical images gathered at different stages of dissolution of GeO 2 (0-3 days). (c) CV measurement of MOS capacitors at $1 \mathrm{MHz}$ for post-growth and post regrowth $\mathrm{GeO}_{2}$ samples. (d) Dielectric constant of GeO 2 post-growth and post-regrowth. 
See supplementary material for extracting the relative dielectric constant $\kappa$ from $\mathrm{CV}$ measurement and atomic force microscopy of $\mathrm{GeO}_{2}$ after immersed in tap water. Two figures (Figs. S1 and S2) are also included.

This publication is based on the work supported by the King Abdullah University of Science and Technology (KAUST).

${ }^{1}$ X. Huang, Y. Liu, S.-W. Hwang, S.-K. Kang, D. Patnaik, J. F. Cortes, and J. A. Rogers, Adv. Mater. 26, 7371 (2014).

${ }^{2}$ S. K. Kang, R. K. J. Murphy, S. W. Hwang, S. M. Lee, D. V. Harburg, N. A. Krueger, J. H. Shin, P. Gamble, H. Y. Cheng, S. Yu, Z. J. Liu, J. G. McCall, M. Stephen, H. Z. Ying, J. Kim, G. Park, R. C. Webb, C. H. Lee, S. J. Chung, D. S. Wie, A. D. Gujar, B. Vemulapalli, A. H. Kim, K. M. Lee, J. J. Cheng, Y. G. Huang, S. H. Lee, P. V. Braun, W. Z. Ray, and J. A. Rogers, Nature 530, 71 (2016).

${ }^{3}$ M. K. Murthy and H. Hill, J. Am. Ceram. Soc. 48, 109 (1965).

${ }^{4}$ O. H. Johnson, Chem. Rev. 51, 431 (1952).

${ }^{5}$ M. F. Ehman, K. Vedam, W. B. White, and J. W. Faust, J. Mater. Sci. 6, 969 (1971).

${ }^{6}$ Q. Xie, S. Deng, M. Schaekers, D. Lin, M. Caymax, A. Delabie, X.-P. Qu, Y.-L. Jiang, D. Deduytsche, and C. Detavernier, Semicond. Sci. Technol. 27, 074012 (2012).

${ }^{7}$ J. Oh and J. C. Campbell, J. Electron. Mater. 33, 364 (2004).

${ }^{8}$ C. O. Chui, S. Ramanathan, B. B. Triplett, P. C. McIntyre, and K. C. Saraswat, IEEE Electron Device Lett. 23, 473 (2002).

${ }^{9}$ E. S. Goh, T. Chen, C. Sun, and Y. Liu, J. Appl. Phys. 107, 024305 (2010).
${ }^{10}$ X. Zeng, Q. Song, J. Li, W. Yuan, H. Duan, and L. Liu, J. Cleaner Prod. 90, 55 (2015).

${ }^{11}$ J.-G. Park, Ph.D. thesis, The University of Arizona, Tucson, 1993.

${ }^{12}$ J. F. Binder, Ph.D. thesis, Ecole Polytechnique Federale De Lausanne, Lausanne, 2012.

${ }^{13}$ N. R. Murphy, J. T. Grant, L. Sun, J. G. Jones, R. Jakubiak, V. Shutthanandan, and C. V. Ramana, Opt. Mater. 36, 1177 (2014).

${ }^{14}$ N. Taoka, K. Ikeda, Y. Yamashita, N. Sugiyama, and S.-I. Takagi, Semicond. Sci. Technol. 22, S114 (2006).

${ }^{15}$ D. Briggs and J. T. Grant, Surface Analysis by Auger and X-ray Photoelectron Spectroscopy (IM Publications, Chichester, 2003), p. 31.

${ }^{16}$ A. Molle, M. N. K. Bhuiyan, G. Tallarida, and M. Fanciulli, Appl. Phys. Lett. 89, 083504 (2006).

${ }^{17}$ V. Grossi, L. Ottaviano, S. Santucci, and M. Passacantando, J. Non-Cryst. Solids 356, 1988 (2010).

${ }^{18}$ K. Kita, C. H. Lee, T. Nishimura, K. Nagashio, and A. Toriumi, ECS Trans. 19, 101 (2009).

${ }^{19}$ See http://onlinelibrary.wiley.com/ for Inductively Coupled Plasma Optical Emission Spectrometry. Encyclopedia of Analytical Chemistry: Instrumentation and Applications; accessed 9 October 2016.

${ }^{20}$ J. E. Sansonetti, W. C. Martin, and S. L. Young, J. Phys. Chem. Ref. Data 34, 1734 (2005).

${ }^{21}$ C. Ekberg and P. L. Brown, Hydrolysis of Metal Ions (Wiley-VCH Verlag GmbH \& Co. KGaA, Weinheim, 2016), p. 39.

${ }^{22}$ R. A. Larson, Reaction Mechanisms in Environmental Organic Chemistry (Lewis Publishers, Boca Raton, 1994), p. 105.

${ }^{23}$ S. K. Upadhyay, Chemical Kinetics and Reaction Dynamics (Springer Science \& Business Media, New York, 2006), p. 46.

${ }^{24}$ K. Martens, C. O. Chui, G. Brammertz, B. D. Jaeger, D. Kuzum, M. Meuris, M. Heyns, T. Krishnamohan, K. Saraswat, and H. E. Maes, IEEE Trans. Electron Devices 55, 547 (2008). 